\title{
What Happened to Him Using the Freight Elevator: Fall from Height or Caught Between?
}

\author{
Hyoung Joong Kim, \\ Joo Young $\mathrm{Na}$ \\ Forensic Medicine Division, \\ National Forensic Service, Seoul, \\ Korea
}

Received : July 17, 2013

Revised : July 28, 2013

Accepted : August 23, 2013

Corresponding Author : Joo Young $\mathrm{Na}$ Division of Forensic Medicine, National Forensic Service, 139 Jiyang-ro, Sinwol-dong, Yangcheon-gu, Seoul 158-707, Korea.

TEL : +82-2-2600-4814

FAX : +82-2-2600-4828

E-mail : pdrdream@gmail.com
There has been an increase in the incidence of elevator-related accidents in the Republic of Korea. Every year, approximately 10 20 elevator-related fatalities are reported in the Republic of Korea. According to research from the United States, 'falls' were the most common cause of death, followed by 'caught in/between'. In such investigations, it is important to distinguish between the manners of death. Herein, we report an elevator-related fatality, which required careful forensic investigation to determine the cause of death. A thorough forensic autopsy and reinvestigation of the death scene by medical examiners were required to determine if the death was caused as a result of the deceased falling from from a height or being caught in between the elevator and the wall of building.

Key Words : Elevator, Accident, Fall, Caught in/between

\section{Introduction}

Elevator accidents cause about 30 deaths and 17,000 serious injuries annually in the United States alone." In the Republic of Korea, the number of elevator accidents is increasing as more elevators are installed every year. ${ }^{2)}$ About 10 20 fatalities involving elevators are reported each year in the Republic of Korea. ${ }^{31}$ 'Falls' are the most common cause of death and 'caught in/betweens' are the second most common. ${ }^{11}$ We report a case of elevator fatality which required careful differentiation between the two common causes of death.

\section{Case Presentation}

A 53-year-old man was found dead on the roof of a freight elevator car installed on an outer surface of a four-story building in the autumn. The decedent was a thread reseller. The factory in the building asked him to take back several boxes of defective thread he had supplied. And he went to the building to get back those on the previous evening. At the death scene, the elevator car was on the ground level. The elevator system lacked doors and structures to separate the freight car from the building wall. Five boxes of defective thread were inside on the floor of the elevator car. He was lying on the roof of the elevator car near the building wall (Fig. 1). Police assumed the 
cause of death to be a fall from the building.

The deceased showed multiple curvilinear facial lacerations. They were located between the left ear lobe and right side of the chin. Left lower quadrant of facial skin was flayed (Fig. 2a). Disruption of masseter muscles and crushed fracture of mental protuberance were noted. A fragment of black rubbery material was found within the crushed surface (Fig. 2b). Two narrow parallel lines of abrasion (width: $0.5 \mathrm{~cm}$ and $1.0 \mathrm{~cm}$ ) connecting the chin and the medial end of the right clavicle were noted accompanying smaller linear abrasions scattered parallel (Fig. 2c). And we thought these parallel marks matched up with bricks on the building wall (Fig. 2d). Additionally several fragments of dried soft tissue were found on the lower horizontal frame of the third floor window. Two horizontal lines of contusion (distance: $6.5 \mathrm{~cm}$ ) were present at the back of neck (Fig. 3a). And we thought theses horizontal lines matched up with width between a frame bar of the roof of the elevator car and the building wall (Fig. 3b). Several bracket shaped abrasions were on left shoulder and both thighs. Posterolateral aspect of the left thigh showed three linear abrasions coursing the whole length of the thigh. Each of ankles and dorsal surfaces of feet showed a linear laceration.
On internal examination, diffuse hemorrhage and rupture of deep neck muscle were found. Along with fracture and separation of atlas and axis, fractures of facial bones (mandible, maxillae, nasal bone, left zygoma) were noted but scalp and calvarium were intact. Brain showed generalized severe cerebral edema and subarachnoid hemorrhage of the right temporal area. Multifocal atherosclerosis was found in the basal arteries of the cerebrum. Coronary arteries showed atherosclerosis (which obstructs about 50\% of the cross-sectional area in proximal portion of left anterior descending artery, about $10 \%$ in left circumflex artery). Mild congestion of abdominal organs, mild fatty liver and chronic inflammation and fibrosis of both kidneys were noted. About $160 \mathrm{~g}$ of barely digested gastric contents and foci of gastric mucosal ecchymoses were found. Both thighs showed subcutaneous hemorrhage under the previously mentioned abrasions.

Toxicology analysis was negative. Infrared spectroscopy analysis showed materialistic characteristics were identical between the black rubbery material from the mandible fracture site and silicone adhesive from the outer surface of the building.

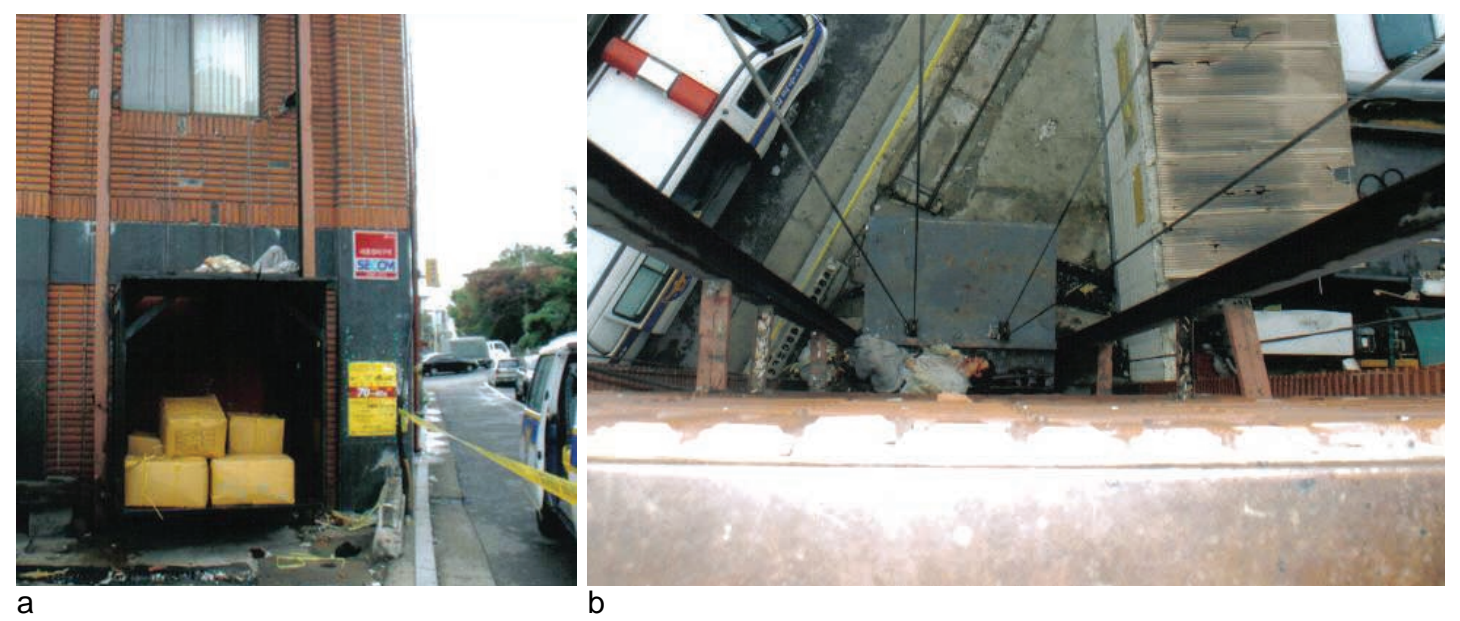

Fig. 1. The freight elevator system is facilitated on the outside of the factory building. The elevator car is seen on the ground floor. The deceased is seen on the roof of the elevator car and several boxes of the goods are loaded inside of the elevator car which has no door with just iron bar frames structured in a cubic form (a). It is seen from the third floor window outside. The dead body is placed on the roof of the elevator car, near the building wall (b). 


\section{Discussion}

Not uncommonly, assumption or interpretation based on death scene investigation by police could be wrong, which is frequently corrected by appropriate forensic scene investigation and autopsy. The presenting case, too, was initially informed as a 'fall' on police death scene investigation but was found to be a 'caught in/between' accident after resonable interpretation through scene investigation and autopsy by medical examiners.

The height of the building and the characteristics of injuries were considered in deciding the cause of the death. Assuming the height of one floor to be $3 \sim 4$ meters, the estimated falling distance is $9 \sim 12$ meters. Falls from the estimated height are reported to cause multiple injuries of whole body including head, neck, extremities, thorax, abdomen and internal organs and fractures of cranial vault, skull base and extremities in considerable number of cases. ${ }^{\left.4^{-7}\right)}$ The most common fatal injuries of decedents fell from height were on head and chest. ${ }^{81}$ One report showed the most common cause of death was head trauma $158 \%$, in fall distance less than $9 \mathrm{~m}$ ) and multiple trauma $(75 \%$, in fall distance more than $9 \mathrm{~m}) .{ }^{91}$ Overall, the characteristics of the decedent (laceration and fracture of facial area with intact scalp and calvarium and no limb fracture) were not in accordance with the findings reported on literature.

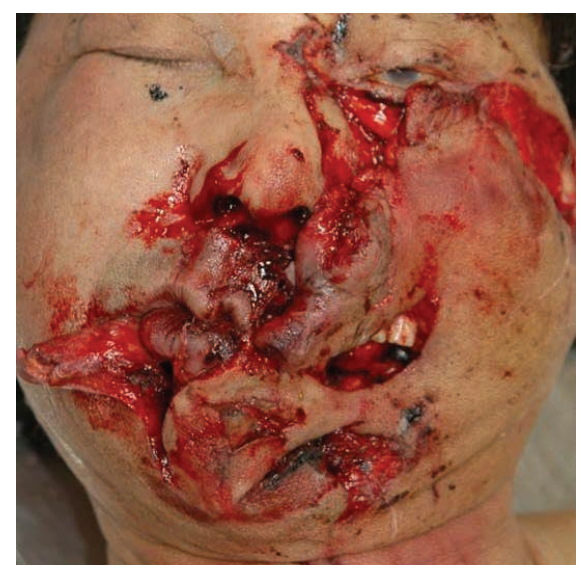

a
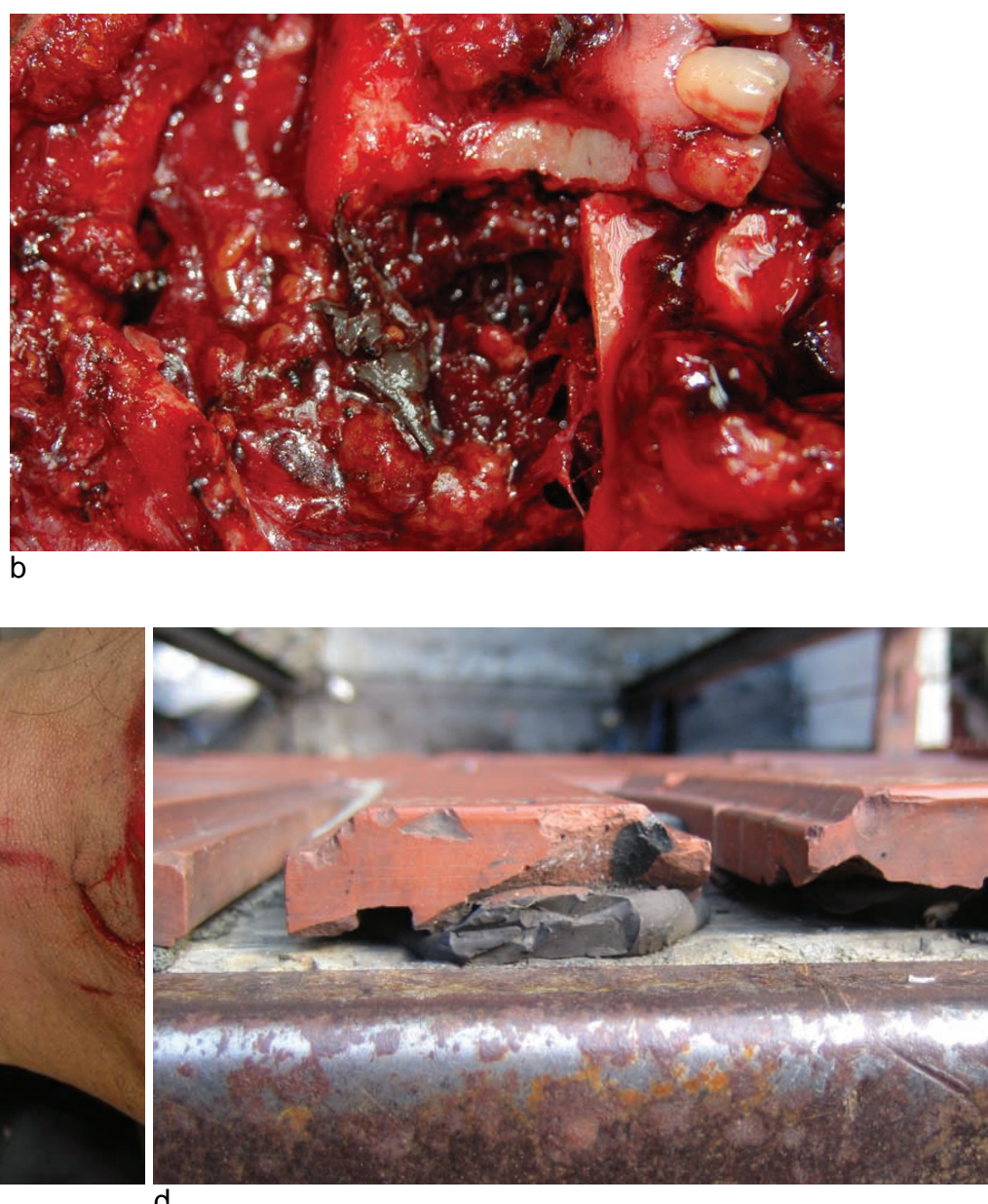

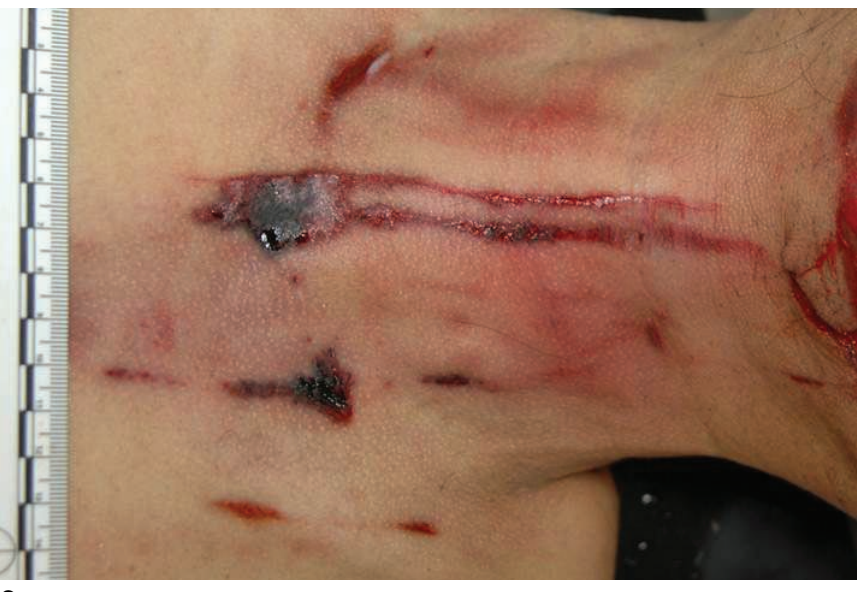

Fig. 2. Flayed and crushed pattern of lacerations are developed on the orofacial area (a). A black silicon rubber fragment is seen in the mandibular fracture site (b). Linear abrasions from the chin to the clavicular area are formed parallel to the neck (c). And theses parallel marks are thought to match up with bricks on the building wall, also there are black silicon rubber materials (d). 


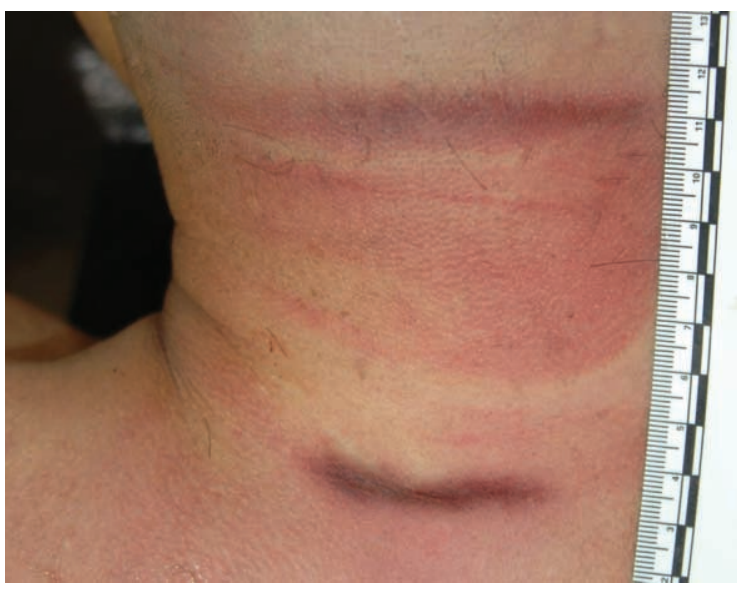

a

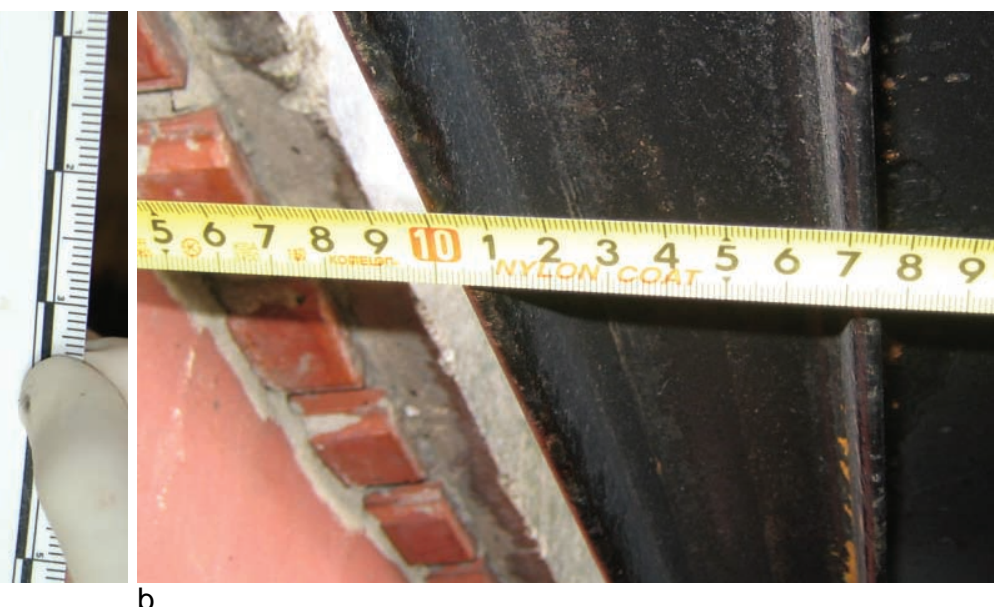

Fig. 3. The parallel linear contusions on the posterior neck (a) are a form of patterned injury, being compatible with the iron frame bars of the roof of the elevator car (b).

Along with these contradictory findings, the silicone fragment found from face and the adipose tissue on the building wall lead to the conclusion that he was caught between the elevator car frame and the building wall. The posterior neck of the decedent might have been impinged between a frame bar of the roof of the elevator car and the building wall somehow when the elevator was descending. The body might have dragged down along the wall making the linear abrasions and lacerations all over the body lengthwise. The shearing force could have caused the facial and spinal injuries with traction pattern. As the elevator came down, the gap between the elevator roof and the building wall must have been widened enough to allow the head pass through at windows. After the head and neck was freed from the gap, the body might have been moved toward on the roof of the elevator car as found on the death scene by gravitational force.

The death could have been prevented with proper safety measurement done before the accident. The elevator of this case violated Korean government regulations regarding elevators in several aspects (i.e. not installing doors). In addition to the proper installment of elevators, timely and continued maintenance must be made because older elevators have higher accident rate. ${ }^{2)}$ This case was required considerable amount of time and effort in careful autopsy, death scene investigation, and contemplation over the cause of death with review of literature. One should remember 'falls' and 'caught in/between' are the most common cause of the elevator accident fatalities and cases like this need to be approached carefully. Because, generally speaking, accident should be considered in 'caught in/between' more than in 'falls' cases, and medical examiner should consider cause, mechanism and responsibility in accidental cases to prevent such a case.

\section{References}

1. McCann M, Zaleski N. Deaths and injuries involving elevators and escalators. Georgia: Silver Spring; 2006. p. 1-2.

2. Lee JC. Risk factors and improvement of elevator. Seoul: Korea Elevator Safety Technology Institute; 2007. p. 1-5.

3. Korea Elevator Safety Institute. Accident statistics, Seoul (2013). Available at http://kesi.or.kr

4. Li L, Smialek JE. The investigation of fatal falls and jumps from heights in Maryland (1987-1992). Am J Forensic Med Pathol 1994;15:295-9.

5. Gupta SM, Chandra J, Dogra TD. Blunt force lesions related to the heights of a fall. Am J Forensic Med Pathol 1982;3:35-43.

6. Warner KG, Demling RH. The pathophysiology of free-fall injury. Ann Emerg Med 1986;15:1088-93.

7. Steedman DJ. Severity of free-fall injury. Injury 1989;20:259-61.

8. Beale JP, Wyatt JP, Beard D, et al. A five year study of high falls in Edinburgh. Injury 2000;31:503-8.

9. Turk EE, Tsokos M. Pathologic features of fatal falls from height. Am J Forensic Med Pathol 2004;25:194-9. 